\section{An introduction to transoesophageal echocardiography: II. Clinical applications}

Purpose: As progress has been made in the acquisition of cardiac images with transoesophageal echocardiography, the technique has moved from the confines of the cardiology laboratory into the operating room, the intensive care unit, and the emergency department. This has afforded anaesthetists the opportunity to become familiar with, and develop expertise in its practice. The purpose of this article is to present a review of transoesophageal echocardiography with reference to anaesthetic practice.

Source: The principle source of material was a computerized Medline ${ }^{\mathrm{TM}}$ search of the English language literature from 1986 to 1995.

Principle findings: After discussing the technique of probe insertion, and describing some of the standard images, transoesophageal echocardiography's clinical utility is critically assessed. Comparisons with available monitoring techniques are made with reference to ventricular function, valvular heart disease, pericardial, aortic and congenital heart disease, and the management of the multiple traumatized patient. Issues of certification and maintenance of competence are also discussed.

\section{Key words}

ANAESTHESIA: cardiac;

ARTERIES: aorta;

COMPLICATIONS: trauma;

EQUIPMENT: Doppler, echocardiography;

HEART: echocardiography, transoesophageal, myocar-

dial function; heart valves; pericardium, congenital defects;

MEASUREMENT TECHNIQUES: echocardiography.

From the Department of Anaesthesia* and the Division of Cardiology $\dagger$, Sunnybrook Health Science Centre, University of Toronto, Toronto, Ontario, and the Department of Anaesthesia, $\ddagger$ Queen Elizabeth II Health Sciences Centre, Dalhousie University, Halifax, Nova Scotia.

Address correspondence to: Dr. Donald Oxom, Department of Anaesthesia, Sunnybrook Health Science Centre, 2075 Bayview Ave., Toronto, Ontario, Canada M4N 3M5.

Fax: 416-480-6039.

Accepted for publication 15th October, 1995.
Donald Oxorn MD CM FRCPC, ${ }^{\dagger} \dagger$

Gerald Edelist MD FRCPC,*

Mark Stafford Smith MD CM FRCPC $\ddagger$
Conclusion: Although the benefit of transoesophageal echocardiography is intuitive in many clinical situations, in others, it has not been shown to improve upon presently existing monitoring techniques. The need for adequate training and collaboration with cardiology colleagues is emphasized.

Objectif: Tout en progressant sur le plan technique, l'échographie transoesophagienne a débordé le cadre du laboratoire de cardiologie pour atteindre celui de la salle d'opération, de l'unité de soins intensifs et de la salle d'urgence. Il a été alors possible pour l'anesthésiste de se familiariser avec la technique et d'accroître sa compétence. L'objectif de ce travail est de présenter une perspective de l'échographie transoesophagienne appliquée au domaine de l'anesthésie.

Source: La source principale de cette revue est une recherche par ordinateur sur Medline ${ }^{\mathrm{TM}}$ des publications en anglais de 1986 à 1995.

Données principales: Après discussion de l'insertion de la sonde et la description d'images standard, l'utilité de l'échographie transoesophagienne est évaluée. Des comparaisons avec les techniques de monitorage de la fonction ventriculaire en usage sont établies en ce qui concerne la cardiopathie valvulaire, les maladies péricardiques, aortiques et les cardiopathie congénitales ainsi que la gestion du polytraumatisé. Les probème de la certification et du maintien de la compétence sont aussi discutés.

Conclusions: Bien que les bénéfice de l'échographie transoesophagienne se rapproche de l'intuition dans plusieurs situations, dans d'autres, on n'a pas montré sa supériorité sur les autres techniques de monitorage actuelles. La nécessité d'une formation appropriée et la collaboration avec les collègues cardiologues sont soulignées.

\section{Contents}

Introduction

Patient preparation and probe insertion

Standard views

- Three chamber view

- Four chamber view

- Ventricular trans gastric short axis

- Descending aorta 
Clinical Utility

- Ventricular function

- Systolic function

- Ischaemia monitoring

- Myocardial infarction

- Diastolic function

- Valvular heart disease

- Mitral regurgitation

- Mitral stenosis

- Aortic regurgitation

- Aortic stenosis

- Tricuspid regurgitation

- Valve prosthesis and repair

- Endocarditis

- Pericardial effusion

- Aortic diseases

- Trauma

- Embolic disorders

- Congenital heart disease

Care and cleaning of equipment

Certification, and maintenance of competence

Summary

Appendix

- Bibliography

References

Since the initial description of cardiac ultrasound using a transducer introduced through the oesophagus, ${ }^{1}$ transoesophageal echocardiography (TEE) has evolved to allow the generation of high quality, real time ultrasonic images in multiple planes. With the addition of Doppler capability, the ability to assess normal and pathological flows is facilitated. By obviating the need to have access to the patient's thorax, the utility of TEE in anaesthetized and critically ill patients was quickly recognized. Transoesophageal echocardiography has become an integral part of the management of patients undergoing cardiac surgical procedures and, because of the wealth of haemodynamic data yielded, has had an impact on the management of critically ill patients. ${ }^{2,3}$ In this article, we will focus on the standard views and the clinical indications for TEE as they apply to the operating room and intensive care unit. We will conclude with a discussion of education, certification, and maintenance of competence in TEE.

\section{Patient preparation and probe insertion}

The anaesthetist will most often be called upon to perform TEE in patients who are anaesthetized with their tracheas intubated. Awake patients requiring TEE will be encountered less commonly; these individuals have traditionally fallen into the domain of the cardiologist, but practice is institution-specific. Irrespective of which area of the hospital TEE is being performed, full resuscitative facilities including suction must be readily available.

Questions regarding dysphagia, previous surgery or radiation of the upper gastrointestinal tract, abnormal dentition, cervical spine disease, a bleeding diathesis, and allergies are important components of a general medical history. A suitable period of fasting is important in patients in whom tracheal intubation is not planned. A complete cardiorespiratory physical examination should be followed by a detailed examination of the mouth, teeth, and oropharynx. Dentures, if present, should be removed.

In patients who will remain awake for the TEE examination, the mouth and oropharynx are anaesthetized with topical application of lidocaine. Specific nerve blocks may also be used. ${ }^{4}$ Light intravenous sedation with short acting agents may be employed. The use of muscarinic antagonists for mucosal drying is advocated by some, although there is no objective evidence that probe insertion is facilitated. ${ }^{5}$ The patient is placed in a lateral decubitus position, and the lubricated probe is introduced. Patient swallowing facilitates its passage into the upper oesophagus.

The anaesthetized patient whose trachea is intubated is usually positioned supine. The probe is passed blindly into the oesophagus; flexion of the patient's head, digi-

LIST OF ABBREVIATIONS

TEE = transoesophageal echocardiography

$\mathrm{LA}=$ left atrium

$\mathrm{MV}=$ mitral valve

$\mathrm{LV}=$ left ventricle

LVOT = left ventricular outflow tract

$\mathrm{AV}=$ aortic valve

$\mathrm{RV}=$ right ventricle

$\mathrm{RA}=$ right atrium

IAS = interatrial septum

TV = tricuspid valve

IVS = interventricular septum

PA $=$ pulmonary artery

PCWP = pulmonary capillary wedge pressure

$\mathrm{EDA}=$ end diastolic area

$\mathrm{ESA}=$ end systolic area

TTE $=$ transthoracic echocardiography

SWMA = segmental wall motion abnormality

HOCM = hypertrophic obstructive cardiomyopathy

SAM = systolic anterior motion

$\mathrm{IE}=$ infective endocarditis

ASE = American Society of Echocardiography

ASA = American Society of Anesthesiologists

SCA $=$ Society of Cardiovascular Anesthesiologists 
tal manipulation, temporary deflation of the endotracheal tube cuff and pharmacological paralysis may increase the rate of success. Alternatively, direct laryngoscopy may be used to direct the probe.

Extreme force should never be used in the passage of the probe. The use of bite blocks is encouraged, even in patients who appear well anaesthetized.

Close monitoring of cardiorespiratory function is important. Pulse oximetry is mandatory in the patient receiving conscious sedation, and the administration of supplemental oxygen by nasal prongs is encouraged. In patients with marginal cardiorespiratory reserve in whom TEE is deemed essential, consideration must be given to endotracheal intubation.

The use of prophylactic antibiotics in situations of high risk for endocarditis remains controversial. The incidence of bacteraemia is low following esophageal intubation, and probably due to contamination. ${ }^{6.7}$

There are several absolute contraindications to the use of TEE. Oesophageal obstruction by stricture or tumour, oesophageal diverticulum, laceration, or fistula, or active upper GI bleeding preclude its use. In patients with oesophagitis, oesophageal varices, remote gastric surgery, gastric ulcer, hiatus hernia, cervical spine disease, or a bleeding diathesis, the benefits of TEE must be weighed against the increased risk conferred by the patient's underlying medical condition.

Several large surveys ${ }^{8,9}$ attest to the low incidence of complications with, and high patient acceptance of transoesophageal echocardiography. The incidence of serious morbidity including oesophageal rupture, pulmonary complications, arrythmias, angina, hypotension, pulmonary oedema, cardiac arrest, pharyngeal bleeding, and laryngospasm was $0.18-0.5 \%$. In close to 14,000 patients, only two deaths were reported. ${ }^{8,9}$

\section{Standard views}

Standard views of multiplane transoesophageal echocardiography will be described. For an in-depth description, the reader is referred to more complete reviews ${ }^{10-12}$ and standard references appended to this article.

\section{Three chamber view}

With the transducer in the horizontal plane, the first structures to be encountered are the great vessels at the base of the heart: the superior vena cava, the ascending aorta, and the main pulmonary artery. Advancement of the probe to approximately $30 \mathrm{~cm}$ from the incisors yields the three chamber view, consisting of the left atrium (LA), mitral valve (MV), left ventricle (LV) and left ventricular outflow tract (LVOT), the aortic valve (AV), ascending aorta, and the right ventricle (RV) (Figure 1). Slight withdrawal of the probe and $30^{\circ}$ rota-

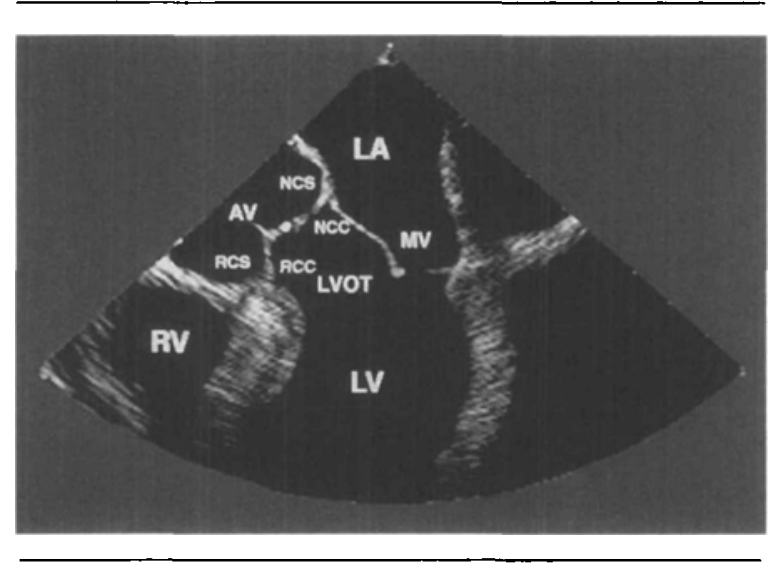

FIGURE 1 Three chamber view. The non coronary and right coronary sinuses of Valsalva (NCS, RCS) give rise to the non and right coronary cusps (NCC, RCC) of the aortic valve. $L A=$ left atrium, MV $=$ mitral valve, $\mathrm{LV}=$ left ventricle, $\mathrm{LVOT}=$ left ventricular outflow tract, $\mathrm{RV}=$ right ventricle, $\mathrm{AV}=$ aortic valve.

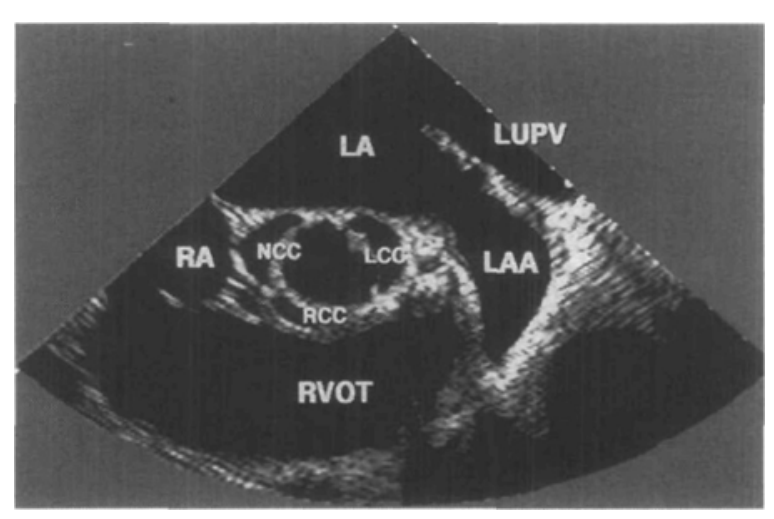

FIGURE 2 Aortic valve, horizontal section, In systole, the aortic leaflets (LCC, RCC, NCC = left, right, and non coronary cusps) are open. LA = left atrium, LUPV = left upper pulmonary vein, LAA = left atrial appendage, RA = right atrium, RVOT = right ventricular outflow tract. Not visualized in this figure are the right and left coronary arteries, which are often seen emanating from the right and left sinuses of Valsalva.

tion of the transducer allows a cross sectional view of the aortic valve and surrounding structures (Figure 2). Rotation of the transducer to $120^{\circ}$ allows a longitudinal assessment of the aortic valve, ascending aorta, and LVOT (Figure 3).

\section{Four chamber view}

With the probe returned to the horizontal plane, it is advanced several centimetres and retroflexed. The LVOT, aortic valve, and ascending aorta disappear, and the right atrium (RA), interatrial septum (IAS), tricuspid 


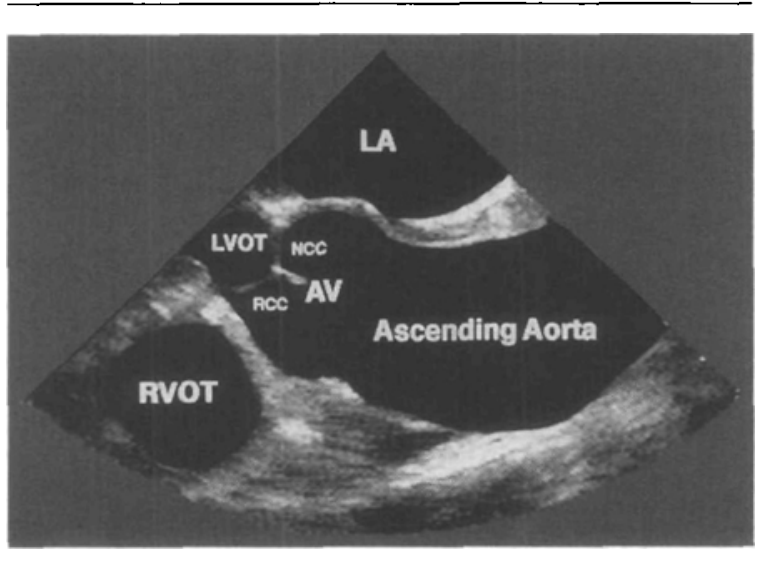

FIGURE 3 Longitudinal section of the aortic valve in diastole; the non and right coronary cusps (NCC, RCC) of the aortic valve (AV) are closed. LA = left atrium, RVOT = right ventricular outflow tract, LVOT $=$ left ventricular outflow tract.

valve (TV), right ventricle and interventricular septum (IVS) come into view (Figure 4, A, B).

\section{Ventricular trans gastric short axis}

At approximately $40 \mathrm{~cm}$ from the incisors, the probe will have reached the level of the diaphragm. Slight resistance may be felt as the probe is advanced into the stomach. With the probe anteflexed, both ventricles will be seen in cross section. Advancement should continue until the antero-lateral (AL) and postero-medial (PM) papillary muscles of the mitral valve are visualized. At this level, the territory of all three coronary arteries is represented, (Figure 5) and the presence or absence of ventricular dysfunction can be determined.

\section{Descending aorta}

At the level of the 3 chamber view, the probe is rotated to face posteriorly. The descending aorta can now be seen in cross section. Advancement of the probe allows more distal portions of the descending thoracic aorta to be seen. Rotation of the transducer 90 degrees allows the aorta to be visualized in longitudinal section (Figure 6, A, B).

\section{Clinical Utility}

\section{Ventricular function}

One of the most important aspects of patient assessment in the operating room and intensive care unit, is the continuous monitoring of cardiovascular function. In healthy patients having minor procedures, ECG display and non-invasive blood pressure determination are usu-
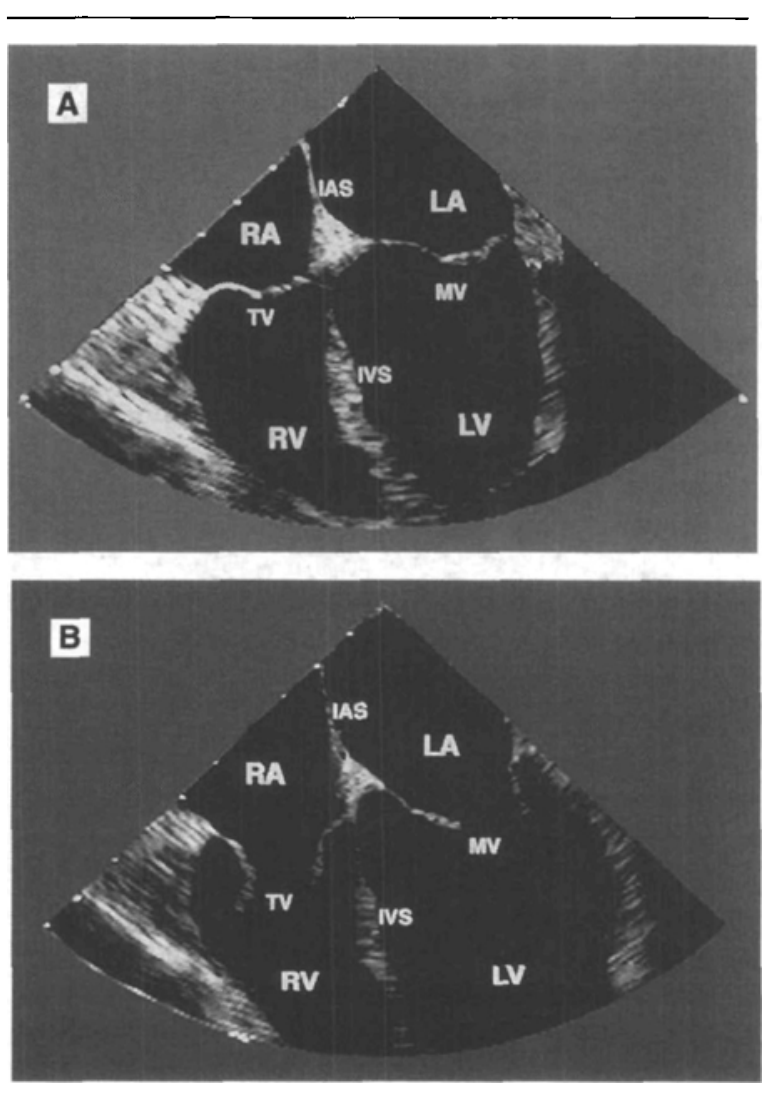

FIGURE 4 (A) and (B). Four chamber view; (A) systole, atrioventricular valves closed, $(B)$ diastole, atrioventricular valves open. $L A=$ left atrium, $M V=$ mitral valve, $L V=$ left ventricle, $R A=$ right atrium, $\mathrm{TV}=$ tricuspid valve, $\mathrm{RV}=$ right ventricle, IAS = inter-atrial septum, IVS = inter-ventricular septum.

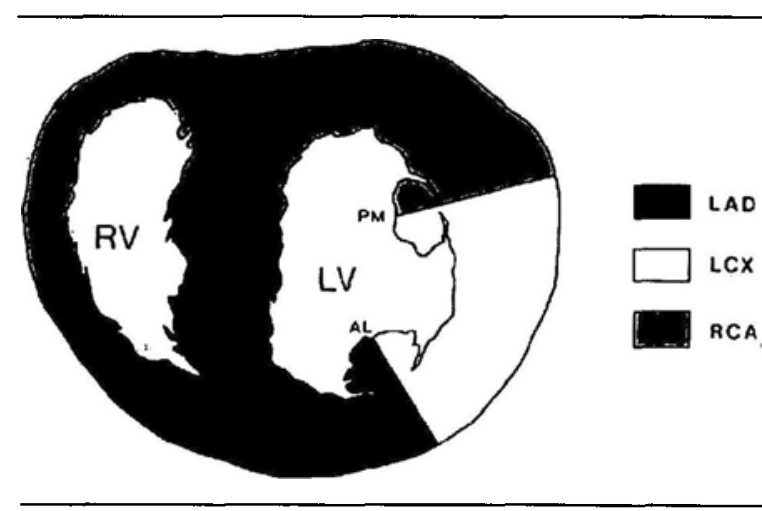

FIGURE 5 Trans gastric short axis: The right and left ventricles are seen in short axis, at the level of the antero-lateral (AL) and posteromedial (PM) papillary muscles of the mitral valve. All three coronary arteries are represented at this level. $\mathrm{LV}=$ left ventricle, $\mathrm{RV}=$ right ventricle, $\mathrm{LAD}=$ left anterior descending artery, $\mathrm{LCX}=$ circumflex artery, RCA = right coronary artery. 

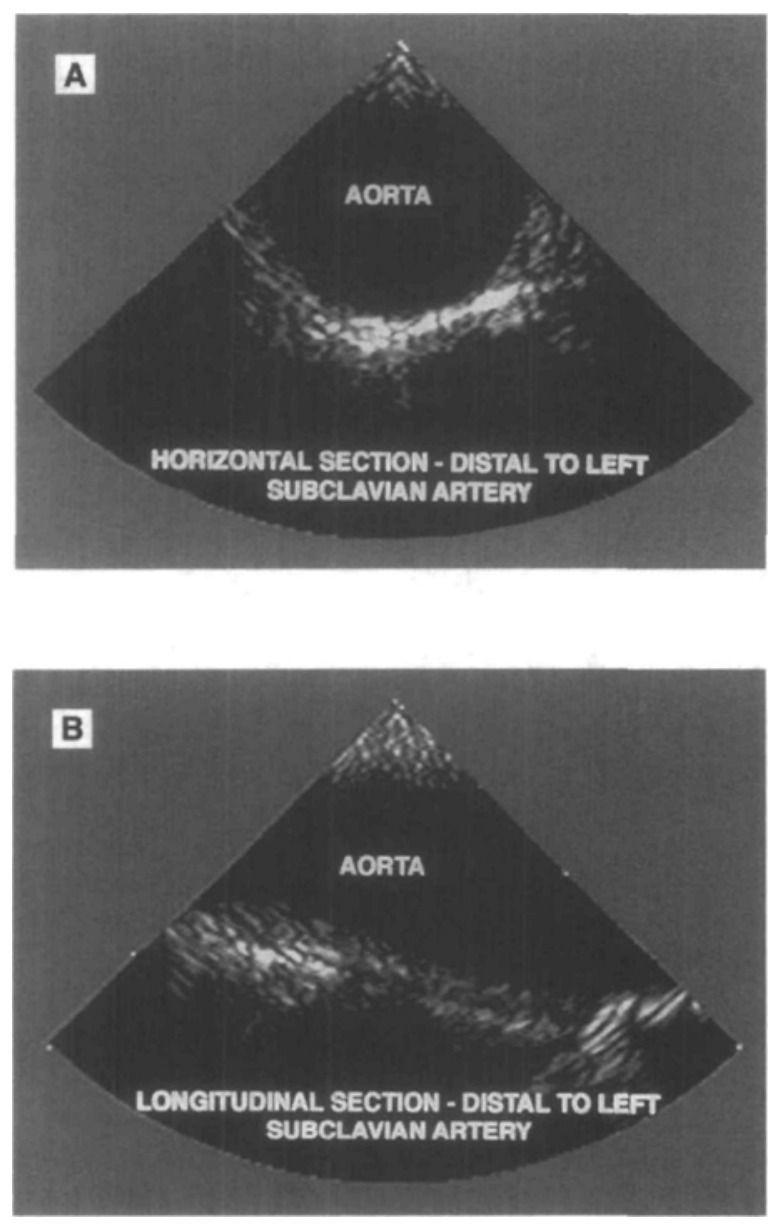

FIGURE 6 (A) and (B). Descending thoracic aorta. (A) horizontal plane, (B) longitudinal plane.

ally sufficient. As surgical complexity increases and patient reserve diminishes, more sophisticated monitors, such as the pulmonary artery (PA) catheter are often employed; because of its well known complications, ${ }^{13}$ anaesthetists have sought less invasive ways of obtaining the same haemodynamic data. As will be seen, TEE fulfills some of these goals, but is not practically suited at present to replace traditional methods.

\section{SYSTOLIC FUNCTION}

Overall systolic function is assessed by the measurement of cardiac output. Perhaps equally important is the quantification of the various components of cardiac output (preload, contractility, and afterload), as the treatment of low cardiac output often depends on which of its components is disturbed. The gold standard in bed- side measurement of cardiac output is thermodilution with the use of the PA catheter. A qualitative assessment of global systolic function may be made echocardiographically by visual inspection of wall motion. This method is accurate and reproducible, but obviously requires an experienced echocardiographer. ${ }^{14}$ Cardiac output may also be measured by TEE and Doppler echocardiography. Mean velocity of blood flow is integrated over the time of one cardiac cycle and multipled by the diameter of the conduit through which the blood passes yielding stroke volume; multiplication by the heart rate gives cardiac output. Comparisons between thermodilution cardiac output and TEE have yielded mixed results. Earlier studies emphasized that difficulties in measurement of the velocity time integral and conduit area ${ }^{15}$ led to poor correlation. Recently, more advanced probes have been used to measure cardiac output across the aortic valve, ${ }^{16}$ the mitral valve, ${ }^{17}$ and the right ventricular outflow tract. ${ }^{18}$ Highly significant correlation coefficients of 0.93 to 0.97 with concurrent thermodilution measurements were found. However, considerable limitations exist with TEE measurement of cardiac output in the operating room. Assumptions above valve orifice geometry are made, and the velocity data from a limited number of heart beats is extrapolated to a time frame of one minute; cardiac rhythms other than sinus, and the presence of valvular and subvalvular disease may introduce error. The appropriate echocardiographic views may be difficult to obtain, especially if the position of the heart is changing as in mediastinal or thoracic surgery.

Preload is defined as the stretch on the myocardium at end diastole, by the blood present in the ventricle. As difficulties exist in the clinical measurement of cardiac volumes, the pulmonary capillary wedge pressure (PCWP) has been employed as a reflection of left atrial pressure and ultimately left ventricular end diastolic volume. This relationship weakens, however, in the presence of changing ventricular compliance. ${ }^{19}$ Preload may be approximated with TEE by the measurement of the end diastolic area (EDA) of the LV, imaged with the trans gastric short axis view at the mid papillary level. This may be done by manual planimetry, or with automated detection of the endocardial border. ${ }^{20}$ When compared with PCWP, EDA has been found to correlate more closely with other indicators of cardiac performance. ${ }^{21,22}$ When measured during aortic reconstructive surgery, EDA was found to correlate closely with end diastolic volume as measured by first pass radionuclide angiography. ${ }^{23}$ Ventricular volumes may be calculated with formulas developed for transthoracic echocardiography (TEE), but there are inherent limitations when similar principles are used with TEE;24 multiple cuts 
must be obtained, the apex of the LV is often not seen, and the time required is prohibitive in the rapidly changing milieu of the operating room.

Measurement of LV contractility is difficult, because most variables thought to reflect it are load sensitive; despite these limitations, ejection fraction has gained wide acceptance as a measure of $\mathrm{LV}$ contractility. It may be quantitated with TEE by comparing end systolic and end diastolic areas of the left ventricle, imaged with the trans gastric short axis view at the mid papillary level; close correlation with ejection fraction measurement by radionuclide angiography ${ }^{23}$ and epicardial echocardiography ${ }^{25}$ is seen. The end systolic pressurevolume relation is a load independent index of contractility, ${ }^{26}$ and has been estimated by combining measurement of echocardiographically derived LV end systolic area with femoral arterial pressure. ${ }^{27}$ The major limitation of the studies to date is that they examine patients with normal ventricular function. It is possible that areas of ventricular dysfunction outside the mid papillary level may not be represented in calculations of contractility, and lead to its overestimation.

Left ventricular wall stress has been proposed as a measure of afterload ${ }^{28}$ but its measurement is cumbersome and not readily applicable to management of patients in the operating room. It has not been found to correlate with systemic vascular resistance as measured by PA catheter. ${ }^{21}$

In summary, although most components of systolic function can be accurately measured with TEE, most anaesthetists and intensivists are familiar with the haemodynamic data acquired from pulmonary artery catheterization and, as at present, it will remain the mainstay for routine haemodynamic monitoring. In departments where TEE equipment and expertise are readily available, it may be used in selective cases where rapid assessment of cardiovascular function is needed.

\section{ISCHAEMIA MONITORING}

When normal systolic contraction occurs, both the myocardium and endocardium thicken and move inwards. Abnormal contraction may be manifest as hypokinesis, (diminished thickening), akinesis (absent thickening), or dyskinesis (paradoxical movement outwards). Transoesophageal echocardiography has inherent appeal as a monitor of intraoperative myocardial ischaemia. The trans gastric short axis view of the $\mathrm{LV}$ at the mid papillary level has representation from myocardium supplied by all three major coronary arteries; new segmental wall motion abnormalities (SWMA) detected by TEE are most often the result of acute ischaemia. Smith et al. ${ }^{29}$ found that during cardiac or major vascular surgery, the appearance of SWMA was an earlier and more sensitive indicator of myocardial ischaemia than five lead ECG. In patients with SWMA that persisted to the conclusion of surgery, there was a high incidence of postoperative myocardial infarction. Leung, ${ }^{30}$ in a study of patients undergoing coronary artery bypass grafting, also found a higher incidence of SWMA than ischaemic ECG changes. The SWMAs were seen most often after cardiopulmonary bypass, and portended a poor outcome. Other investigators have demonstrated a poor correlation between SWMA and adverse outcomes. ${ }^{31}$

The varied findings are a result of many factors. The criteria for a clinically important SWMA has not been validated. As well, not all acute SWMAs are due to ischaemia. Changes in loading conditions, tethering of normal myocardium adjacent to a region of acutely ischaemic myocardium, and post ischaemic, "stunned" myocardium may all present as an SWMA. Most intraoperative studies have monitored the LV by the trans gastric short axis plane at the mid papillary level; ischaemic myocardium at the apex or base of the $\mathrm{LV}$, or the RV in its entirety might not be appreciated. ${ }^{32}$

Although echocardiography is more sensitive than ECG at detecting intraoperative ischaemia, and can be used in the presence of rhythm disorders such as left bundle branch block, the probe is generally inserted after the induction of anaesthesia, whereas ECG monitoring may be undertaken throughout the perioperative period. Diagnosis of intraoperative ischaemia is not as accurate when wall motion analysis is undertaken in the operating room as it is by offline analysis of intraoperative echocardiograms. ${ }^{29,30,33}$

Although TEE holds promise in the detection of intraoperative myocardial ischaemia, it appears more predictive of adverse outcomes in cardiac than non cardiac surgery. The use of multiple echocardiographic planes will probably add to its clinically utility. It remains, however, a technique that is highly dependent on the skill of the operator, and in need of validation as an on line monitor in the operating room.

\section{MYOCARDIAL INFARCTION}

Transoesophageal echocardiography is well suited for the diagnosis of myocardial infarction, by the demonstration of akinetic or dyskinetic myocardium. Complications of myocardial infarction, such as mitral regurgitation, ventricular septal defect, left ventricular aneurysm, pump failure, and cardiac tamponade are readily demonstrated. In the setting of cardiopulmonary resuscitation, TEE has been used as a diagnostic tool, as a monitor of resuscitative efforts, and in the evaluation of new methods of resuscitation..$^{34}$ 


\section{DIASTOLIC FUNCTION}

Symptoms of congestive heart failure are usually attributed to impaired systolic function, left sided valvular regurgitation and stenosis, and ventricular restriction as seen with pericardial disease. Impaired ventricular filling may be secondary to diastolic dysfunction, and may produce symptoms which are suggestive of the aforementioned entities. ${ }^{35,36}$ The invasive assessment of diastolic function is clinically impractical; however, parameters of left ventricular filling, obtained noninvasively by Doppler determination of pulmonary venous and mitral inflow velocities, ${ }^{37-39}$ closely approximate left ventricular filling dynamics as measured by cineangiography $^{37}$ and nuclear cardioangiography. ${ }^{40}$ The major limitation in the Doppler assessment of diastolic function is that loading conditions, as well as ventricular relaxation and compliance, affect trans mitral and pulmonary venous Doppler velocities.

\section{Valvular heart disease}

For the anaesthetist, assessment of valvular heart disease is most important in patients undergoing cardiac surgery, for either valve replacement or repair, and the critically ill patient with native or prosthetic valve dysfunction. Transoesophageal echocardiography can be used to assess valve leaflet structure and motion, the severity of regurgitation, and the presence of vegetations. Doppler techniques permit calculation of valve areas and pressure gradients.

\section{MITRAL REGURGITATION}

Inferential echocardiographic evidence of severe mitral regurgitation includes increased left atrial size, an enlarged, hyperdynamic left ventricle, and abnormal leaflet motion (prolapse, flail). Colour flow Doppler is the most commonly used method for the demonstration of regurgitant flow (Figure 7). The use of planimetry allows calculation of the mosaic regurgitant jet area, which correlates closely with transthoracic and angiographic assessment of regurgitation severity; a maximal jet area $<3$ or $>6 \mathrm{~cm}^{2}$ predicts mild or severe mitral regurgiation respectively, with $98 \%$ accuracy compared to angiography. ${ }^{41,42}$ The presence of a large area of turbulent flow on the ventricular side of the mitral valve may indicate of severe degrees of mitral regurgitation, and mathematical analysis of the velocity profile of the pre-mitral turbulence allows quantitation of the regurgitant flow. ${ }^{43}$ Eccentric jets which hug the wall of the left atrium are typically seen with mitral valve prolapse and are difficult to quantitate. Measurement of the regurgitant jet width at its origin may allow differentiation between mild and severe mitral regurgitation. ${ }^{44}$

Visualizing either the left or right upper pulmonary veins as they enter the left atrium allows pulse Doppler assessment of pulmonary venous flow velocities. During systole, blood flows from the pulmonary vein towards the transducer and into the left atrium. With severe mitral regurgitation, blood flow during systole flows from the LV into the LA and down the pulmonary vein away from the transducer. This reversal of systolic flow is indicative of severe mitral regurgitation. ${ }^{45}$

Intraoperatively, a semi-quantitative assessment combined with pulmonary venous Doppler velocities is usually undertaken; the quantitative methods are too cumbersome for practical use.

\section{MITRAL STENOSIS}

Mitral stenosis occurs almost exclusively in the setting of rheumatic heart disease, and has distinctive echocardiographic characteristics. The posterior leaflet is thickened and immobile, and the anterior leaflet assumes a hockey stick appearance during diastole, due to commissural fusion. The subvalvular apparatus may be diseased as well. Doppler can be used to calculate the peak and mean velocities of mitral inflow, with sampling usually done at the leaflet tips; the modified Bernoulli equation allows estimation of peak and mean pressure gradients across the mitral valve. ${ }^{46}$ Doppler analysis of mitral inflow velocities can also be used to calculate the valve area. The software contained in the ultrasound machine uses the modified Bernoulli equation to calculate the pressure gradient between the LA and LV throughout early diastolic filling. The rate with which the pressure gradient diminishes correlates with the mitral valve's effective orifice size. ${ }^{47}$ When sampling flow for Doppler velocity assessment, it is always important to ensure that the sampling location is consistent, as even slight movement of the TEE probe relative to the valve orifice may lead to error.

Planimetry can be used to directly measure the mitral valve area. Co-existant mitral regurgitation can be determined with the use of colour Doppler.

As the degree of stenosis progresses, the left atrium enlarges, and spontaneous echo contrast (an appearance similar to smoke) indicative of stagnant blood becomes evident. ${ }^{48}$ Spontaneous echo contrast also heralds an increased risk of systemic arterial embolization. ${ }^{49}$ Direct visualization of the left atrial appendage may reveal thrombii, especially if the patient is in atrial fibrillation and has not been anticoagulated.

\section{AORTIC REGURGITATION}

Transoesophageal echocardiography correlates of aortic regurgitation include valvular abnormalities such as bicuspid valve, dilated ascending aorta, and left ventricular dilation. It is most easily recognized with the use of 


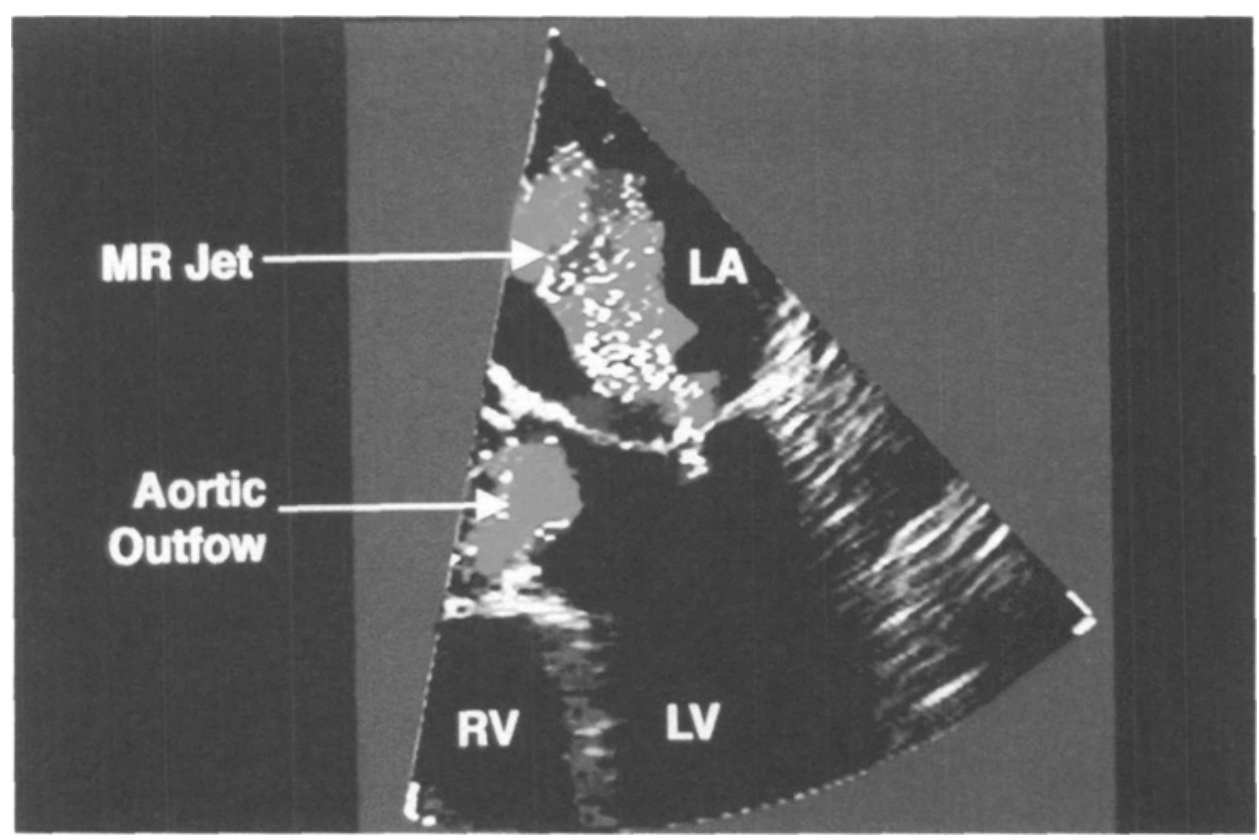

FIGURE 7 Mitral regurgitation. With colour Doppler applied to the three chamber view in systole, a regurgitant jet is seen in the left atrium. Also appreciated is normal systolic flow in the LVOT. The area of the regurgitant jet is $7.2 \mathrm{~cm}^{2}$, which is consistent with severe mitral regurgitation. ${ }^{41,42}$

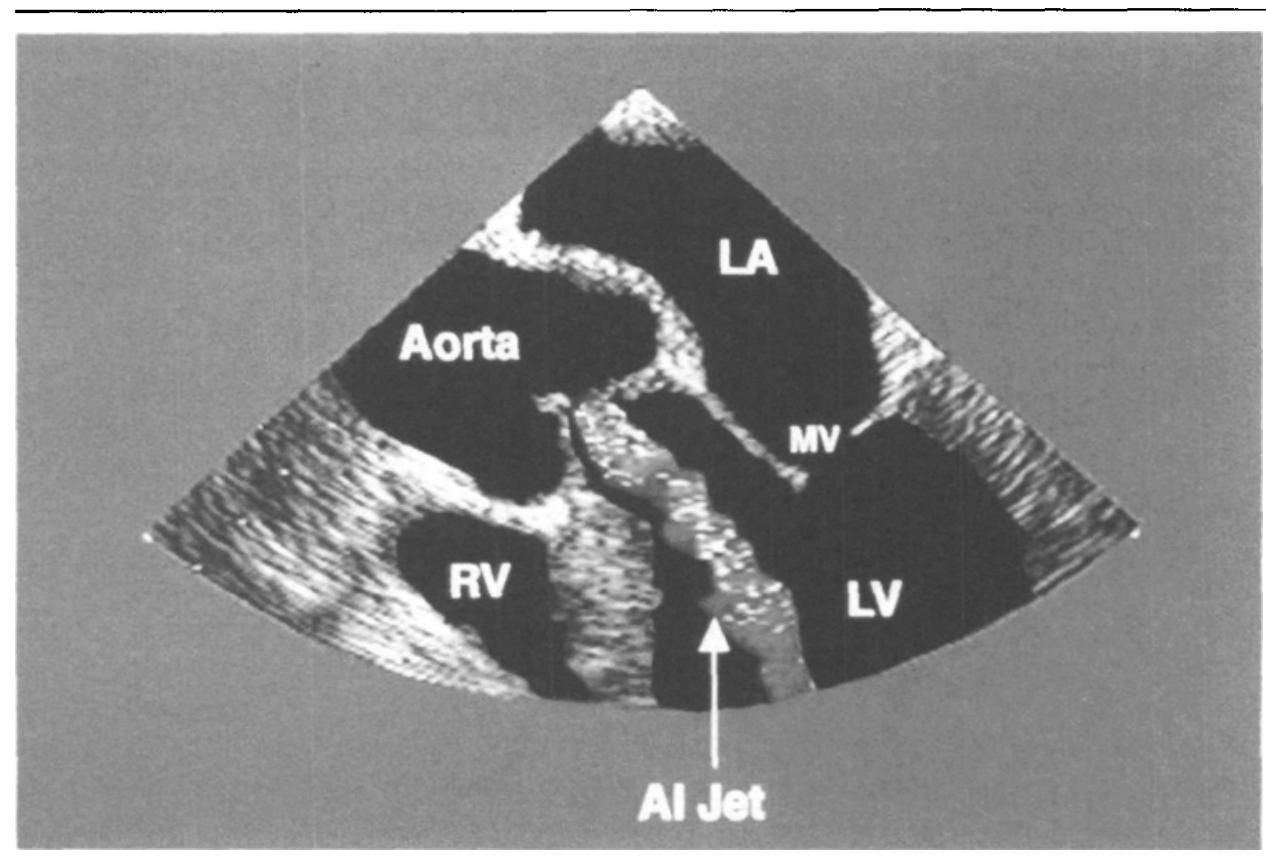

FIGURE 8 Aortic regurgitation. With colour Doppler applied to the three chamber view in diastole, a regurgitant jet is seen passing through the aortic valve into the LVOT and LV. 
colour Doppler. With the aortic valve imaged in cross section, flow can be seen occurring during diastole. With longitudinal imaging, the regurgitant flow can be followed from the aorta, through the aortic valve, and into the LVOT (Figure 8). When the jet height on the ventricular side of the aortic valve is divided by the LVOT diameter, a value of 0.6 or greater indicates severe aortic regurgitation with a $96 \%$ accuracy compared with angiography. ${ }^{50}$ Spectral Doppler can also be used to estimate the severity of regurgitation. As regurgitant volume increases, the time for aortic and left ventricular diastolic pressures to equalize diminishes, and the Doppler velocity signal falls off more rapidly. ${ }^{51} \mathrm{By}$ imaging the descending thoracic aorta and using pulse wave Doppler to determine the direction of flow, diastolic flow reversal is indicative of severe aortic regurgitation. ${ }^{52}$

\section{AORTIC STENOSIS}

The echocardiographic hallmarks of aortic stenosis include heavy calcification and restricted opening of valve leaflets, and dilation of the ascending aorta. There is concentric hypertrophy of the left ventricle, and systolic function is usually preserved until late in the course of the disease. Colour Doppler is used to determine if there is coexistent aortic regurgitation.

Doppler can be used to calculate the peak pressure gradients across the aortic valve, in a similar fashion to that described for the mitral valve (Vide supra). In order to sample parallel to aortic flow, a trans gastric image of the ascending aorta must be obtained. ${ }^{53}$ The aortic valve area may be measured by planimetry, ${ }^{54}$ or the continuity equation. ${ }^{55,56}$ The latter technique takes advantage of the fact that flow through the LVOT must equal flow through the aortic valve; multiplication of the Doppler velocity of flow through the LVOT by the LVOT area will equal the Doppler velocity of flow through the aortic valve multiplied by the aortic valve area. As the first three variables are readily measured, the aortic valve area may be calculated.

Obstruction of the LVOT may also occur secondary to subvalvular disease. In hypertrophic obstructive cardiomyopathy (HOCM), there is septal hypertrophy which is disproportionate to the left ventricular free wall. Flow through the narrowed LVOT results in a localized Venturi effect, and systolic anterior motion (SAM) of the anterior mitral leaflet. This causes an obstructive subaortic gradient and mitral regurgitation. Ventricular septal myectomy may be performed in patients refractory to medical management. Intraoperative post myectomy TEE allows assessment of the width of the remaining septum and LVOT, pressure gradients, residual SAM and mitral regurgitation, and postopera- tive complications such as ventricular septal defect and aortic regurgitation. ${ }^{57}$

\section{TRICUSPID REGURGITATION}

If present, measurement of the peak velocity of the regurgitant jet with continuous wave Doppler and application of the modified Bernoulli equation allows calculation of the pressure gradient between the right atrium and right ventricle. If an estimate of right atrial pressure is added, the right ventricular systolic pressure can be approximated; in the absence of pulmonic stenosis, this reflects pulmonary artery systolic pressure, a valve which may aid in the haemodynamic management of critically ill patients.

\section{VALVE PROSTHESES AND REPAIRS}

It is in this area where TEE has had its most valuable impact on anaesthetic and surgical practice. Following the repair of mitral, and aortic valves, Doppler and colour Doppler can be used to asses the presence of residual pressure gradients, regurgitant jets, and LVOT obstruction following the termination of cardio-pulmonary bypass. ${ }^{58-61}$ This follow up study must be done under conditions which reflect the patient's preoperative haemodynamic state. If necessary, cardio-pulmonary bypass can be re-instituted and further repair or valve replacement undertaken.

The flow characteristics of numerous mechanical and bioprosthetic valves has been reported ${ }^{62,63}$ Assessment is done in the operating room at the time of surgery, and postoperatively if malfunction is suspected. The valve sewing ring is examined for areas of dehisence, and the moving elements of the valve are carefully inspected. Gross malfunction is usually suspected on clinical grounds. ${ }^{64,65}$ As with repair, residual pressure gradients, valvular, and paravalvular regurgitant jets are sought.

\section{ENDOCARDITIS}

The use of transoesophageal echocardiography in the diagnosis and management of patients with ineffective endocarditis (IE) has recently been reviewed. ${ }^{66}$ Vegetations move independently from the affected valve, can be seen in more than one ultrasound plane, and have a density different from that of surrounding tissues. A detection rate of close to $100 \%$ is seen in patients with IE assessed by TEE. In most reported studies, diagnostic accuracy was twice that of TTE, especially in patients with prosthetic valves and difficult transthoracic acoustic windows. ${ }^{67,68} \mathrm{~A}$ positive TEE establishes the diagnosis of IE; a negative study in the face of ongoing clinical suspicion dictates the need for follow-up TEE.

The assessment of complications of IE such as 
abscess and fistula formation, and leaflet perforation, is facilitated. ${ }^{69}$

\section{Pericardial effusion}

A pericardial effusion is seen as an echo free space between the epicardium and pericardium. Cardiac tamponade is suggested by the clinical presentation, and collapse of the right atrium and ventricle during diastole. Transoesophageal echocardiography allows assessment of the effects of pericardiocentesis, and has been used to guide surgical drainage of a loculated purulent pericardial effusion. ${ }^{70}$

\section{Aortic diseases}

The thoracic aorta can be viewed in its entirety, with the caveat that portions of the proximal arch are occasionally not visualized because of interposition of the trachea between the aorta and the esophagus. ${ }^{71}$

Transoesophageal echocardiography has become a first line diagnostic tool in the assessment of aortic dissection, with a sensitivity and specificity respectively of $96 \%$ and $86 \%$ in the ascending aorta, $95 \%$ and $94 \%$ in the aortic arch, and $97 \%$ and $94 \%$ in the descending aorta. ${ }^{72}$ As well as visualizing the intimal flap, extravascular blood, aortic insufficiency, and pericardial effusion can also be diagnosed by TEE. Colour Doppler may reveal bi-directional flow in the true and false lumens.

Thoracic aortic aneurysms may be visualized, and TEE has the advantage of being able to delineate secondary effects on cardiac function. ${ }^{73}$

Transoesophageal echocardiography has also been applied to the diagnosis of traumatic disorders of the aorta (Figure 9). Its intrinsic appeal over aortography is the rapidity with which it may be performed in any area of the hospital, and its avoidance of toxic contrast dyes. Although initially lacking adequate numbers of patients and proper blinding, ${ }^{74,75}$ recent studies have shown TEE to compare favourably with aortography. ${ }^{76,77}$ Artifacts have been reported, ${ }^{78-80}$ and only through individual experience will each trauma centre be able to determine when the findings of TEE, both positive and negative for aortic injury will preclude aortography. ${ }^{81}$

Atherosclerotic disease of the aortic arch as diagnosed by TEE is a predictor of ischaemic stroke, 82 and during cardiopulmonary bypass, atheroembolii from the aorta have been implicated as a cause of embolic stroke. ${ }^{83}$ This has led some authors to recommend femoral cannulation in this clinical setting. ${ }^{84}$ Transoesophageal echocardiography has been reported to detect ascending aortic atherosclerosis with a sensitivity of $100 \%$ and a specificity of $60 \% .{ }^{85}$ Although a negative TEE, therefore, implies an extremely low likelihood of

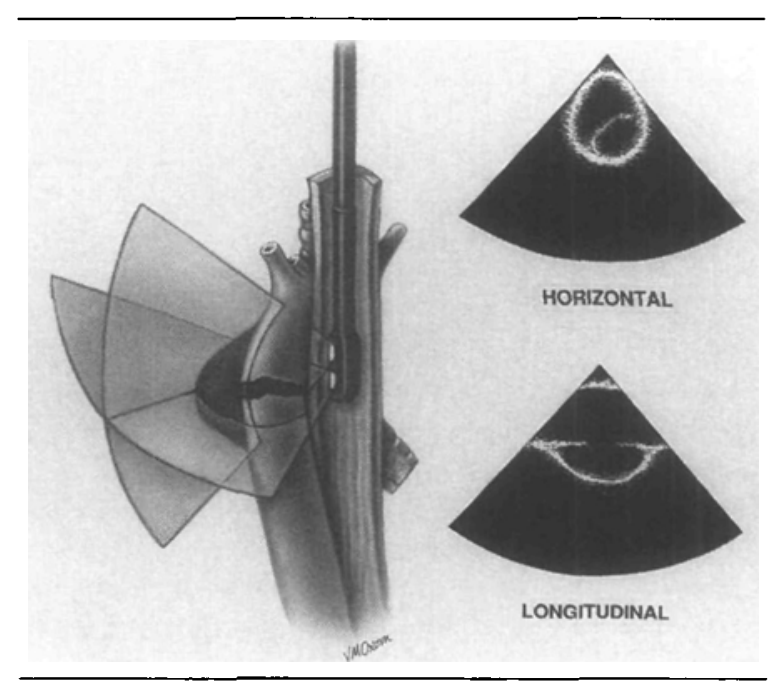

FIGURE 9 Traumatic aortic disruption. Left hand panel: The biplane TEE probe is seen in the esophagus. Orthogonal ultrasound planes image the descending aorta, which has a traumatic tear and false aneurysm. Right hand panel: the horizontal and longitudinal ultrasound images, which demonstrate a flap of tissue within the aortic Jumen.

important plaque, a positive study should ideally be followed by epicardial echocardiography performed by the surgical team following sternotomy.

\section{Trauma}

In patients with thoracic trauma, TEE may be helpful in clinical assessment. ${ }^{75,86,87}$ In addition to injuries of the aorta, cases of valvular injury, ${ }^{88-91}$ pericardial tamponade,,$^{92}$ penetrating ${ }^{93-95}$ and nonpenetrating ${ }^{96,97}$ cardiac injury have been reported in which TEE played a diagnostic role. Caution must be exercised, lest the technique be used in the setting of oesophageal injury.

\section{Embolic disorders}

In the evaluation of patients with embolic stroke, TEE is recognized as an important tool. ${ }^{98}$ It has also been used to intraoperatively diagnose left atrial myxomas prior to recurrent embolization. ${ }^{99,100}$ There have been a number of case reports which attest to TEE's utility in the diag. nosis and monitoring of treatment of proximal pulmonary embolism. ${ }^{101-104}$ Embolii may be seen in the main pulmonary artery or its major branches, and as well, secondary effects on right heart function may be delineated.

Following the report of a TEE diagnosed, intraoperative fat embolism, ${ }^{105}$ a number of reports of embolic phenomena during lower limb orthopaedic procedures followed. ${ }^{106-108}$ However, not all instances of echocar- 
diographically documented embolii are followed by clinical changes in cardiorespiratory function, or postoperative sequelae.

Venous air embolism can be seen in settings such as pulmonary barotrauma and sitting position neurosurgical procedures, and the use of TEE in their diagnosis has been described. ${ }^{109}$ TEE may also be used to detect intracardiac air following valvular surgery, and may assist with the various maneuvres designed to eliminate air prior to separation from cardio-pulmonary bypass.

\section{Congenital heart disease}

Ultrasound of the heart is used routinely with or, increasingly, without cardiac catheterization for intracardiac morphology and haemodynamic assessment in the management of infants and children with congenital heart disease. Since most cardiac structures are easily visualized in children using transthoracic echocardiography, TEE has played a lesser role in routine investigation of paediatric cardiac patients than in adults. However children with abnormal heart location, poor precordial ultrasonic windows (e.g., chest wall abnormalities, previous median sternotomy), or whose management requires detailed images of posterior cardiac structures (e.g., pulmonary veins, Fontan circulation) benefit from diagnostic TEE studies; these are usually performed under general anaesthesia. Adult TEE probes are too large for children $<20 \mathrm{~kg}$; this led to the development of miniaturized paediatric TEE probes, first reported in $1989 .{ }^{10}$ Until recently, available paediatric TEE probes had reduced image quality compared with adult transthoracic and TEE probes, due to fewer ultrasound crystals. "' However, high quality paediatric TEE probes for biplane 2-D and Doppler imaging are now available with diameters as small as $7 \mathrm{~mm}$, which can safely be used in neonates as small as $2.3 \mathrm{~kg} .{ }^{112}$

Echocardiography during cardiac surgery in young children began with the application of sterile transthoracic TEE probes directly onto the surface of the heart (epicardial echocardiography). Only with the advent of miniaturized TEE probes did continuous intraoperative echocardiography imaging become possible. Both epicardial and transoesophageal echocardiography have proved to be reliable intraoperative tools, ${ }^{113}$ used for detailed prebypass imaging of cardiac anatomy, and post-repair assessment of cardiac function and quality of repair, ${ }^{114,115}$ while TEE can also be used in intensive care settings for diagnosis and management of postoperative complications. ${ }^{115}$

Transoesophageal echocardiography is now established as an important tool in the diagnosis, and perioperative management of paediatric congenital heart disease. Although the challenge of miniaturization of TEE probes has delayed introduction of this technology, the benefits of its availability to anaesthetists, first demonstrated in adult cardiac surgery, now also appear to be relevant to heart surgery for infants and children.

\section{Care and cleaning of equipment}

Guidelines have been published for the cleaning and sterilization of gastroscopes, and these same guidelines have been applied to TEE probes. ${ }^{116}$ After the study has been completed and the probe withdrawn, thorough rinsing with tap water is followed by $20 \mathrm{~min}$ of soaking in a glutaraldehyde solution. The probe is once again rinsed with tap water, and $20 \mathrm{~min}$ are allowed for any residual glutaraldehyde to evaporate. Commercial sleeves may be used to protect the probe when used in patients with infectious diseases.

\section{Certification, and maintenance of competence}

With the advent of new technologies, it behooves our professional associations to establish guidelines for training, so that proper credentialling may be undertaken. Guidelines have been published by the American Society of Echocardiography (ASE) for physician training and maintenance of competence in transoesophageal echocardiography. ${ }^{17}$ For non-cardiologists, it is recommended that the training be equivalent to that received during a cardiology fellowship. This would entail Level 2 training in TTE (performance of approx. 300 cases), performance of 50 transoesophageal studies, and annual completion of 50-75 TEE studies to maintain competence. Not only is the absolute number of studies performed and interpreted important, but a varied case mix is equally essential. ${ }^{118}$ The ASE also recognized that anaesthetists without the aforementioned training may wish to use TEE for intraoperative wall motion analysis. This practice was deemed acceptable if there were physicians with expertise in diagnostic echocardiography available when needed for consultative purposes.

The American Society of Anesthesiologists (ASA) and the Society of Cardiovascular Anesthesia (SCA) are developing guidelines for training in, and the indications for intraoperative TEE. An executive summary has been circulated to SCA members, which will ultimately lead to a final document. For anaesthetists interested in becoming involved with TEE, it is well worth reading. Three categories of indications for intraoperative TEE are defined, based on the support of available scientific evidence (strong, weak, or little evidence). Specific physician training objectives are also outlined.

The educational programme in intraoperative TEE at the Cleveland Clinic has recently been published. ${ }^{119}$ Over one year, the trainee is exposed to TTE, outpatient TEE, intraoperative TEE, and finally, supervised TEE 
combined with clinical anaesthesia duties. An accompanying editorial ${ }^{120}$ proposed that different approaches to TEE training were feasible, such as a mentor programme in which TEE skills are gradually acquired in close collaboration with an expert in TEE. This would allow clinicians who are unable to dedicate time to TEE training to develop proficiency. Individual institutions must determine what amount of instruction is acceptable. It was stressed that regardless of his or her level of expertise, the anaesthetist must never let the performance of TEE interfere with clinical duties. In many instances, it is desirable to have one individual administer anaesthesia, while another performs the TEE.

A recent survey has demonstrated extreme variability in anaesthesia based TEE practice. ${ }^{121}$ In 98 academic departments surveyed, anaesthetists were responsible for study interpretations in half, with cardiologists responsible in the remainder. The amount of training ranged from "informal or short course" in 53\% of anaesthetists, to "fellowship, residency or other" in the remainder.

The individual primarily responsible for the interpretation of TEE studies, whether cardiologist or anaesthetist, should be an individual with dedicated training in echocardiography. Development of training guidelines by anaesthesia societies may aid in this regard. In order to assure maintenance of competence, there is a need for ongoing collaboration between anaesthetists and cardiologists. ${ }^{122}$

There are no standards currently published by a Canadian professional body.

\section{Summary}

When should anaesthetists become actively involved in the performance and interpretation of TEE

Purchase of the equipment necessary for TEE monitoring requires a financial outlay of approximately $\$ 50,000.00$ for a multiplane probe, and $\$ 150,000.00$ to $\$ 250,000.00$ for an echocardiographic ultrasound machine. The decision to embark on such a programme must take many factors into account.

Indications for TEE based on strong evidence include the diagnosis of life threatening haemodynamic disturbances in surgical and critically ill patients, valvular, congenital, and hypertrophic surgery, and the diagnosis of diseases of the thoracic aorta. These are clinical entities in which other monitoring modalities may yield insufficient diagnostic information. Less clear cut is the use of TEE in the intraoperative monitoring of cardiac function and the detection of myocardial ischaemia, as other less expensive monitors are readily available.

It would seem reasonable, therefore, for anaesthesia departments actively engaged in the management of patients requiring cardiopulmonary bypass to embark on a program of TEE monitoring, recognizing that its success will hinge largely on the training and dedication of the staff involved. In our department, TEE is used most often in open heart procedures, and in the assessment of haemodynamically unstable trauma patients. In departments not involved with these activities, its implementation cannot be justified.

Although some may venture that TEE is better left to cardiologists, I believe that TEE performed by properly trained anaesthetists adds to the quality of patient care, and can only enhance our image amongst our peers and trainees.

\section{Acknowledgements}

We wish to thank Dr. Cam Joyner for reviewing the manuscript, and Valerie Oxorn for her illustrations.

\section{Appendix}

\section{Bibliography}

Feigenbaum $H$. Echocardiography. 5th ed. Philadelphia: Lea \& Febiger, 1994.

Oka Y, Goldiner PL. Transesophageal Echocardiography. Philadelphia: J.B. Lippincott, 1992.

de Bruijn NP, Clements FM (Eds.). Intraoperative use of Echocardiography. Philadelphia: J.B. Lippincott, 1991. Freeman WK, Seward JB, Khandheria BK, Tajik AJ (Eds.).

Transesophageal Echocardiography. Boston: Little, Brown and Company, 1994.

\section{References}

1 Frazin L, Talano JV, Stephanides L, Loeb HS, Kopel L, Gunnar RM. Esophageal echocardiography. Circulation 1976; 54: 102-8.

2 Oh $J K$, Seward JB, Khandheria BK, et al. Transesophageal echocardiography in critically ill patients. Am J Cardiol 1990; 66: 1492-5.

3 Poelaert JI, Trouerbach J, De Buyzere M, Everaert J, Colardyn FA. Evaluation of transesophageal echocardiography as a diagnostic and theraputic aid in a critical care setting. Chest 1995; 107: 774-9.

4 Reed AP. Sensory blockade for difficult passage of transesophageal echocardiography probes. J Am Soc Echocardiogr 1992; 5: 375-84.

5 Gorscan J III, Thornton JK, DiLucente L, Ziady GM, Katz $W E$. A double-blind trial of glycopyrrolate for transesophageal echocardiography. J Am Soc Echocardiogr 1993; 6: 200-4.

6 Völler H, Spielberg C, Schroder K, Gast D, Schröder R. Frequency of positive blood cultures during transesophageal echocardiography. Am J Cardiol 1991; 68: 1538-40. 
7 Gal RA, Gaeckle TC, Gadasalli S, Kubota JM, Robbins WG, Schmidt DH. Chemoprophylaxis before transesophageal echocardiography in patients with prothetic or bioprosthetic cardiac valves. Am J Cardiol 1993; 72 : 115-7.

8 Daniel WG, Erbel R, Kasper W, et al. Safety of transesophageal echocardiography. A multicenter survey of 10,419 examinations. Circulation 1991; 83: 817-21.

9 Khandheria BK, Oh J. Transesophageal echocardiography: state of the art and future directions. Am J Cardiol 1992; 69: 61H-75H.

10 Seward JB, Khandheria BK, Freeman WK, et al. Multiplane transesophageal echocardiography: image orientation, examination technique, anatomic correlations, and clinical applications. Mayo Clin Proc 1993; 68: 523-51.

11 Pandian NG, Hsu T-L, Schwartz SL, et al. Multiplane transesophageal echocardiography. Echocardiography 1992; 9: 649-66.

12 Seward JB, Khandheria BK, Edwards WD, Oh JK, Freeman WK, Tajik AJ. Biplanar transesophageal echocardiography: anatomic correlations, image orientation, and clinical applications. Mayo Clin Proc 1990; 65: 1193-213.

13 Practice guidelines for pulmonary artery catheterization. Anesthesiology 1993; 78: 380-94.

14 Stamm RB, Carabello BA, Mayers DL, Martin RP. Twodimensional echocardiographic measurement of left ventricular ejection fraction: prospective analysis of what constitutes an adequate determination. Am Heart J 1982; 104: 136-44.

15 Sahn DJ. Determination of cardiac output by echocardiographic Doppler methods: relative accuracy of various sites for measurement (Editorial). J Am Coll Cardiol 1985; 6: 663-4.

16 Darmon P-L, Hillel Z, Mogtader A, Mindich B, Thys D. Cardiac output by transesophageal echocardiography using continuous-wave Doppler across the aortic valve. Anesthesiology 1994; 80: 796-805.

17 Hozumi T, Shakudo M, Applegate R, Shah PM. Accuracy of cardiac output estimation with biplane transesophageal echocardiography. J Am Soc Echocardiogr 1993; 6: 62-8.

18 Maslow A, Douglas P, Haering J, Comunale M. Measurement of cardiac output by pulsed wave Doppler of the right ventricular outflow tract. Anesth Analg 1995; 80: S303.

19 Douglas PS, Edmunds LH, St. John Sutton M, Geer R, Harken $A H$, Reichek $N$. Unreliability of hemodynamic indexes of left ventricular size during cardiac surgery. Ann Thorac Surg 1987; 44: 31-4.

20 Gorscan J III, Gasior TA, Mandarino WA, Deneault LG, Hattler BG, Pinsky MR. On-line estimation of changes in left ventricular stroke volume by transesophageal echocar- diography automated border detection in patients undergoing coronary artery bypass grafting. Am J Cardiol 1993; 72: 721-7.

21 Thys DM, Hillel Z, Goldman ME, Mindich BP, Kaplan JA. A comparison of hemodynamic indices derived by invasive monitoring and two-dimensional echocardiography. Anesthesiology 1987; 67: 630-4.

22 Leung JM, Levine EH. Left ventricular end-systolic cavity obliteration as an estimate of intraoperative hypovolemia. Anesthesiology 1994; 81: 1102-9.

23 Clements FM, Harpole DH, Quill T, Jones RH, McCann $R L$. Estimation of left ventricular volume and ejection fraction by two-dimensional transoesophageal echocardiography: comparison of short axis imaging and simultaneous radionuclide angiography. Br J Anaesth 1990; 64: $331-6$.

24 Smith MD, MacPhail B, Harrison MR, Lenhoff SJ, DeMaria AN. Value and limitations of transesophageal echocardiography in determination of left ventricular volumes and ejection fraction. J Am Coll Cardiol 1992; 19: 1213-22.

25 Konstadt SN, Thys D Mindich BP, Kaplan JA, Goldman $M$. Validation of quantitative intraoperative transesophageal echocardiography. Anesthesiology 1986; 65 : 418-21.

26 Sagawa $K$. The end-systolic pressure-volume relation of the ventricle: definition, modifications and clinical use (Editorial). Circulation 1981; 63: 1223-7.

27 Gorcsan J III, Denault A, Gasior TA, et al. Rapid estimation of left ventricular contractility from end-systolic relations by echocardiography automated border detection and femoral arterial pressure. Anesthesiology 1994; 81: 553-62.

28 Reichek N, Wilson J, St. John Sutton M, Plappert TA, Goldberg S, Hirshfeld JW. Noninvasive determination of left ventricular end-systolic stress: validation of the method and initial application. Circulation 1982; 65: 99-108.

29 Smith JS, Cahalan MK, Benefiel DJ, et al. Intraoperative detection of myocardial ischemia in high-risk patients: electrocardiography versus two-dimensional transesophageal echocardiography. Circulation 1985; 72 : 1015-21.

30 Leung JM, O'Kelly BF, Mangano DT. Relationship of regional wall motion abnormalities to hemodynamic indices of myocardial oxygen supply and demand in patients undergoing CABG surgery. Anesthesiology 1990; 73: 802-14.

31 London MJ, Tubau JF, Wong $M G$, et al. The "natural history" of segmental wall motion abnormalities in patients undergoing noncardiac surgery. Anesthesiology 1990; 73: 644-55.

32 Abel MD, Nishimura RA, Callahan MJ, Rehder K, Ilstrup 
$D M$, Tajik J. Evaluation of intraoperative transesophageal two-dimensional echocardiography. Anesthesiology 1987; 66: 64-8.

33 Villamaria FJ, Abel MD, Nishimura RA. Can transesophageal echocardiography provide useful information in real time in the operating room. Anesth Analg 1988; 67: S246.

34 Redberg RF, Tucker $K$, Schiller NB. Transesophageal echocardiography during cardiopulmonary resuscitation. Cardiol Clin 1993; 11: 529-35.

35 Pagel PS, Grossman W, Haering JM, Warltier DC. Left ventricular diastolic function in the normal and diseased heart. Perspectives for the anesthesiologist (1). Anesthesiology 1993; 79: 836-54.

36 Pagel PS, Grossman W, Haering JM, Warltier DC. Left ventricular diastolic function in the normal and diseased heart. Perspectives for the anesthesiologist (2). Anesthesiology 1993; 79: 1104-20.

37 Rokey R, Kuo LC, Zoghbi WA, Limacher MC, Quinones $M A$. Determination of parameters of left ventricular diastolic filling with pulsed Doppler echocardiography: comparison with cineangiography. Circulation 1985; 71: 543-50.

38 Thomas JD, Weyman AE. Echocardiographic Doppler evaluation of left ventricular diastolic function. Circulation 1991; 84: 977-90.

39 Klein AL, Tajik AJ. Doppler assessment of pulmonary venous flow in healthy subjects and in patients with heart disease. J Am Soc Echocardiogr 1991; 4: 379-92.

40 Samuelsson S, Brodin $L-\AA$. Broman $M$, Öwall A, Settergren $G$. Comparison between transesophageal Doppler echocardiography and nuclear cardioangiography for the evaluation of left ventricular filling during coronary artery bypass grafting. Anesth Analg 1995; 80: 41-6.

41 Castello $R$, Lenzen P, Aguirre F, Labovitz AJ. Quantitation of mitral regurgitation by transesophageal echocardiography with Doppler color flow mapping: correlation with cardiac catheterization. J Am Coll Cardiol 1992; 19: 1516-21.

42 Castello R, Lenzen P, Aguirre F, Labovitz A. Variability in the quantitation of mitral regurgitation by Doppler color flow mapping: comparison of transthoracic and transesophageal studies. J Am Coll Cardiol 1992; 20 : 433-8.

43 Utsunomiya $T$, Ogawa $T$, Doshi $R$, et al. Doppler color flow "proximal isovelocity surface area" method for estimating volume flow rate: effects of orifice shape and machine factors. J Am Coll Cardiol 1991; 17: 1103-11.

44 Tribouilloy C, Shen WF, Quéré J-P, et al. Assessment of severity of mitral regurgitation by measuring regugitant jet width at its origin with transesophageal Doppler color flow imaging. Circulation 1992; 85: 1248-53.
45 Klein AL, Stewart WJ, Bartlett J, et al. Effects of mitral regurgitation on pulmonary venous flow and left atrial pressure: an intraoperative transesophageal echocardiographic study. J Am Coll Cardiol 1992; 20: 1345-52.

46 Feigenbaum $H$. Hemodynamic information derived from echocardiography. In: Feigenbaum H. Echocardiography, 5th ed. Philadelphia: Lea \& Febiger, 1994; 195-8.

47 Feigenbaum $H$. Acquired valvular heart disease. In: Feigenbaum H. Echocardiography, 5th ed. Philadelphia: Lea \& Febiger, 1994: 239-49.

48 Bernstein NE, Demopoulos LA, Tunick PA, Rosenzweig $B P$, Kronzon I. Correlates of spontaneous echo contrast in patients with mitral stenosis and normal sinus rhythm. Am Heart J 1994; 128: 287-92.

49 Hwang J-J, Kuan P, Chen J-J, et al. Significance of left atrial spontaneous echo contrast in rheumatic mitral valve disease as a predictor of systemic arterial embolization: a transesophageal echocardiographic study. Am Heart J 1994; 127: 880-5.

50 Perry GJ, Helmcke F, Nanda NC, Byard C, Soto B. Evaluation of aortic insufficiency by Doppler color flow mapping. J Am Coll Cardiol 1987; 9: 952-9.

51 Labovitz AJ, Ferrara RP, Kern MJ, Bryg RJ, Mrosek DG, Williams $G A$. Quantitative evaluation of aortic insufficiency by continuous wave Doppler echocardiography. J Am Coll Cardiol 1986; 8: 1341-7.

52 Sutton DC, Kluger R, Ahmed SU, Reimold SC, Mark JB. Flow reversal in the descending aorta: a guide to intraopeartive assessment of aortic regurgitation with transesophageal echocardiography. J Thorac Cardiovasc Surg 1994; 108: 576-82.

53 Katz WE, Gasior TA, Quinlan JJ, Gorcsan J III. Transgastric continuous wave Doppler to determine cardiac output. Am J Cardiol 1993; 71: 853-7.

54 Hoffmann NR, Flachskampf FA, Hanrath P. Planimetry of orifice area in aortic stenosis using multiplane transesophageal echocardiography. J Am Coll Cardiol 1993; 22: 529-34.

55 Skjaerpe T, Hegrenaes $L$, Hatle L. Noninvasive estimation of valve area in patients with aortic stenosis by Doppler ultrasound and two-dimensional echocardiography. Circulation 1985; 72: 810-8.

56 Tribouilloy $C$, Shen WF, Peltier $M$, Mirode A, Rey $J L$, Lesbre J-P. Quantitation of aortic valve area in aortic stenosis with multiplane transesophageal echocardiography: comparison with monoplane transesophageal approach. Am Heart J 1994; 128: 526-32.

57 Grigg LE, Wigle ED, Williams WG, Daniel LB, Rakowski $H$. Transesophageal Doppler echocardiography in obstructive hypertrophic cardiomyopathy: clarification of pathophysiology and importance in intraoperative decision making. J Am Coll Cardiol 1992; 20: 42-52.

58 Kalman JM, Buxton BB, Jones EF, Tonkin AM, Lubicz $S$, 
Calafiore $P$. Evaluation of mitral valve repair by intraoperative transoesophageal echocardiography. Aust N Z J Med 1993; 23: 463-9.

59 De Simone R, Lange R, Saggau W, Gams E, Tanzeem A, Hagl $S$. Intraoperative transesophageal echocardiography for the evaluation of mitral, aortic, and tricuspid valve repair. A tool to optimize surgical outcome. Eur J Cardiothorac Surg 1992; 6: 665-73.

60 Jebara VA, Mihaileanu S, Acar $C$, et al. Left ventricular outflow tract obstruction after mitral valve repair. Circulation 1993; 88 [part 2]: 30-4.

61 Lee KS, Stewart WJ, Lever HM, Underwood PL, Cosgrove $D M$. Mechanism of outflow tract obstruction causing failed mitral valve repair. Circulation 1993; 88 [part 2]: 24-9.

62 Feigenbaum $H$. Echocardiography. 5th ed. Philadelphia: Lea \& Febiger, 1994; 678-83.

63 Chambers J, Cross J, Deverall P, Sowton E. Echocardiographic description of the Carbomedics bileaflet prosthetic heart valve. J Am Coll Cardiol 1993; 21: 398-405.

64 Santé P, Renzulli A, Festa M, et al. Acute postoperative block of mechanical prostheses: incidence and treatment. Cardiovasc Surg 1994; 2: 403-6.

65 Pollock SG, Dent JM, Simek CL, et al. Starr-Edwards valve thrombosis detected preoperatively by transesophageal echocardiography. Cathet Cardiovasc Diagn 1994; 31: 156-7.

66 Yvorchuk KJ, Chan $K-L$. Application of transthoracic and transesophageal echocardiography in the diagnosis and management of infective endocarditis. J Am Soc Echocardiogr 1994; 14: 294-308.

67 Lowry RW, Zoghbi WA, Baker WB, Wray RA, Quiñones $M A$. Clinical impact of transesophageal echocardiography in the diagnosis and management of infective endocarditis. Am J Cardiol 1994; 73: 1089-91.

68 Bruss J, Jacobs LE, Kotler MN, Ioli AW. Utility of transesophageal echocardiography in the conservative management of prosthetic valve endocarditis. Chest 1992; 102: 1886-8.

69 Karalis DG, Bansal RC, Hauck AJ, et al. Transesophageal echocardiographic recognition of subaortic complications in aortic valve endocarditis. Clinical and surgical implications. Circulation 1992; 86: 353-62.

70 Golub RJ, McNulty CM, McClellan JR, St. Laurent L, Prior $M W$. Usefulness of transesophageal Doppler echocardiography in the surgical drainage of a loculated purulent pericardial effusion. Am Heart J 1993; 126 : 724-7.

71 Goldstein SA, Mintz GS, Lindsay J Jr. Aorta: comprehensive evaluation by echocardiography and transesophageal echocardiography. J Am Soc Echocardiogr 1993; 6: 634-59.

72 Nienaber CA, von Kodolitsch Y, Nicolas V, et al. The diagnosis of thoracic aortic dissection by noninvasive imaging procedures. N Engl J Med 1993; 328: 1-9.

73 Jacka $M$, Oxorn DC. Pulmonary artery obstruction by aortic aneurysm mimicking pulmonary embolism. Anesth Analg 1995; 80: 185-7.

74 Sparks MB, Burchard KW, Marrin CA, Bean CHG, Nugent WC, Plehn JF. Transesophageal echocardiography. Preliminary results in patients with traumatic aortic rupture. Arch Surg 1991; 126: 711-4.

75 Brooks SW, Young JC, Cmolik B, et al. The use of transesophageal echocardiography in the evaluation of chest trauma. J Trauma 1992; 32: 761-8.

76 Kearney PA, Smith DW, Johnson SB, Barker DE, Smith $M D$, Sapin PM. Use of transesophageal echocardiography in the evaluation of traumatic aortic injury. J Trauma 1993; 34: 696-703.

77 Smith MD, Cassidy JM, Souther S, et al. Transesophageal echocardiography in the diagnosis of traumatic rupture of the aorta. N Engl J Med 1995; 332: 356-62.

78 Oxorn $D$, Towers $M$. Traumatic aortic disruption: false positive diagnosis on transesophageal echocardiography. $\mathbf{J}$ Trauma 1995; 39: 386-7.

79 Appelbe AF, Walker PG, Yeoh JK, Bonitatibus A, Yoganathan AP, Martin RP. Clinical significance and origin of artifacts in transesophageal echocardiography of the thoracic aorta. J Am Coll Cardiol 1993; 21: 754-60.

80 Hust MH, Metzler B, Claußnitzer R, Sebold H, Braun B. Transesophageal echocardiographic artifact mimicking pseudoaneurysm of the aorta. J Am Soc Echocardiogr 1994; 7: 538-41.

81 Vlahakes GJ, Warren WL. Traumatic rupture of the aorta (Editorial). N Engl J Med 1995; 332: 389-90.

82 Amarenco $P$, Cohen A, Tzourio C, et al. Atherosclerotic disease of the aortic arch and the risk of ischemic stroke. $\mathrm{N}$ Engl J Med 1994; 331: 1474-9.

83 Blauth CI, Cosgrove DM, Webb BW, et al. Atheroembolism from the ascending aorta. J Thorac Cardiovasc Surg 1992; 103: 1104-12.

84 Wareing TH, Davila-Roman VG, Barzilai B, Murphy SF, Kouchoukos NT. Management of the severely atherosclerotic ascending aorta during cardiac operations. A strategy for detection and treatment. J Thorac Cardiovasc Surg 1992; 103: 453-62.

85 Konstadt SN, Reich DL, Kahn R, Viggiani RF. Transesophageal echocardiography can be used to screen for ascending aortic atherosclerosis. Anesth Analg 1995; 81: 225-8.

86 Catoire $P$, Orliaguet $G$, Liu $N$, et al. Systematic transesophageal echocardiography for detection of mediastinal lesions in patients with multiple injuries. J Trauma 1995; 38: 96-102.

87 Ellis $J E$, Bender EM. Intraoperative transesophageal echocardiography in blunt thoracic trauma. J Cardiothorac Vasc Anesth 1991; 5: 373-6. 
88 Kantor $G$, Devitt JH. Blunt cardiac injury and intraoperative hypoxaemia. Can J Anaesth 1993; 40: 515-7.

89 Spangenthal EJ, Sekouski B, Bhayana JN, KrawczykJA, Hajduczok $Z D$. Traumatic left ventricular papillary muscle rupture: the role of transesophageal echocardiography in diagnosis and surgical management. J Am Soc Echocardiogr 1993; 6: 536-8.

90 Kleikamp G, Schnepper U, Körtke H, Breymann T, Körfer $R$. Tricuspid valve regurgitation following blunt thoracic trauma. Chest 1992; 102: 1294-6.

91 Turabian $M$, Chan $K-L$. Rupture of mitral chordae tendineae resulting from blunt chest trauma: diagnosis by transesophageal echocardiography. Can J Cardiol 1990; 6: 180-2.

92 Mitchell MM. Detection of occult hemopericardium using intraoperative transesophageal echocardiography. Anesthesiology 1992; 76: 145-7.

93 Porembka DT, Johnson DJ, Hoit BD, Reising J, Davis $K$ $J r$, Koutlas $T$. Penetrating cardiac trauma: a perioperative role for transesophageal echocardiography. Anesth Analg 1993; 77 : 1275-7.

94 McIntyre RC Jr, Moore EE, Read RR, Wiebe RL, Grover $F L$. Transesophageal echocardiography in the evaluation of a transmediastinal gunshot wound: case report. J Trauma 1994; 36: 125-7.

95 Taylor AJ, Rogan KM, Gaither NS, Hull RW, Edwards $F H$. Traumatic coronary artery-atrioventricular fistula. A 26-year follow-up with application of transesophageal echocardiography (Letter). Chest 1992; 102: 1632.

96 Orliaguet $G$, Jacquens $Y$, Riou B, Le Bret F, Rouby J:J, Viars $P$. Combined severe myocardial and pulmonary contusion: early diagnosis with transesophageal echocardiography and management with high-frequency ventilation: case report. J Trauma 1993; 34: 455-7.

97 Goldberg SP, Karalis DG, Ross JJJr. Severe right ventricular contusion mimicking cardiac tamponade: the value of transesophageal echocardiography in blunt chest trauma. Ann Emerg Med 1993; 22: 745-7.

98 DeRook FA, Comess KA, Albers GW, Popp RL. Transesophageal echocardiography in the evaluation of stroke. Ann Intern Med 1992; 117: 922-32.

99 Swenson $J D$, Bailey $P L$. The intraoperative diagnosis of atrial myxoma by transesophageal echocardiogram. Anesth Analg 1995; 80: 180-2.

100 Brooker RF, Butterworth JF IV, Klopfenstein HS. Intraoperative diagnosis of left atrial myxoma. Anesth Analg 1995; 80: 183-4.

101 Rittoo D, Sutherland GR. Acute pulmonary artery thromboembolism treated with thrombolystic: diagnosis and monitoring uses of transesophageal echocardiography. $\mathrm{Br}$ Heart J 1993; 69: 457-9.

102 Langeron $O$, Goarin J-P, Pansard J-L, Riou B, Viars $P$. Massive intraoperative pulmonary embolism: diagnosis with transesophageal echocardiography. Anesth Analg 1992; 74: 148-50.

103 Marti RA, Ricou F, Tassonyi E. Life-threatening pulmonary embolism at induction of anesthesia: utility of transesophageal echocardiography. Anesthesiology 1994; 81: 501-3.

104 Wilson WC, Frankville DD, Maxwell W, Carpenter T, Hastings $R H$. Massive intraoperative pulmonary embolus diagnosed by transesophageal echocardiography. Anesthesiology 1994; 81: 504-8.

105 Pell ACH, Hughes D, Keating J, Christie J, Busuttil $A$, Sutherland GR. Brief report: fulminating fat embolism syndrome caused by paradoxical embolism through a patent foramen ovale. N Engl J Med 1993; 329: 926-9.

106 Parmet JL, Horrow JC, Singer R, Berman AT, Rosenberg $H$. Echogenic embolii upon tourniquet release during total knee arthroplasty: pulmonary hemodynamic changes and emoblic composition. Anesth Analg 1994; 79: 940-5.

107 Cohen JD, Keslin JS, Nili M, Yosipovitch Z, Gassner S. Massive pulmonary embolism and tourniquet deflation. Anesth Analg 1994; 79: 583-5.

108 Fitzgerald R, Mason L, Kanumilli V, Kleinhomer K, Sakamoto A, Johnson $C$. Transient cardiac standstill associated with embolic phenomena diagnosed by intraoperative transesophageal echocardiography during cemented total hip arthroplasty. Anesth Analg 1994; 79: 382-5.

109 Bricker MB, Morris WP, Allen SI, Tonnesen AS, Butler $B D$. Venous air embolism in patients with pulmonary barotrauma. Crit Care Med 1994; 22: 1692-8.

110 Ritter SB, Hillel Z, Narang J, Lewis D, Thys D. Transesophageal real time Doppler flow imaging in congenital heart disease: experience with a new pediatric transducer probe. Dynamic Cardiovascular Imaging 1989; 2: 92-6.

111 Stumper OFW, Sutherland GR. Congenital heart disease in children. In: Sutherland GR, Roelandt JRTC, Fraser AG, Anderson RH (Eds.). Transesophageal Echocardiography in Clinical Practice. London: Gower Medical Publishing, 1991; 15: 1-12.

112 Lam J, Neirotti RA, Lubbers WJ, et al. Usefulness of biplane transesophageal echocardiography in neonates, infants and children with congenital heart disease. Am J Cardiol 1993; 72: 699-706.

113 Muhiudeen IA, Robertson DA, Silverman NH, Haas G, Turley $K$, Cahalan $M K$. Intraoperative echocardiography in infants and children with congenital shunt lesions: transoesophageal versus epicardial echocardiography. $\mathbf{J}$ Am Coll Cardiol 1990; 16: 1687-95.

114 Ungerleider RM, Greely WJ, Sheikl KH, et al. Routine use of intraoperative epicardial echocardiography and Doppler color flow imaging to guide and evaluate repair 
of congenital heart lesions. J Thorac Cardiovasc Surg 1990; 100: 297-309.

115 Ritter $S B$. Transesophageal real-time echocardiography in infants and children with congenital heart disease. $J$ Am Coll Cardiol 1991; 18: 569-80.

116 Weller IVD, Williams CB, Jeffries DJ, et al. Cleaning and disinfection of equipment for gastrointestinal flexible endoscopy: interim recommendations of a working party of British Society of Gastroenterology. Gut 1988; 29: 1134-51.

117 Pearlman AS, Gardin JM, Martin RP, et al. Guidelines for physician training in transesophageal echocardiography: recommendations of the American Society of Echocardiography committee for physician training in echocardiography. J Am Soc Echocardiogr 1992; 5: 187-94.

118 Eisenberg MJ, Rice S, Schiller NB. Guidelines for physician training in advanced cardiac procedures: the importance of case mix. J Am Coll Cardiol 1994; 23: 1723-5.

119 Savage RM, Licina MG, Koch CG, et al. Educational program for intraoperative transesophageal echocardiography. Anesth Analg 1995; 81: 399-403.

120 Cahalan $M K$, Foster $E$. Training in transesophageal echocardiography: in the lab or on the job? (Editorial). Anesth Analg 1995; 81: 217-8.

121 Poterack KA. Who uses transesophageal echocardiography in the operating room? Anesth Analg 1995; 80: 454-8.

122 Hodgins L, Kisslo JA, Mark JB. Perioperative transesophageal echocardiography: the anesthesiologist as a cardiac diagnostician (Editorial). Anesth Analg 1995; 80: 4-6. 